\title{
Article \\ Do Pornography Use and Masturbation Frequency Play a Role in Delayed/Inhibited Ejaculation during Partnered Sex? A Comprehensive and Detailed Analysis
}

\author{
David L. Rowland ${ }^{1, * \mathbb{D}}$, Abigail L. Morrow ${ }^{2}$, Benjamin D. Hamilton ${ }^{1}$ and Krisztina Hevesi ${ }^{3}$ \\ 1 Department of Psychology, Valparaiso University, Valparaiso, IN 46383, USA; ben.hamilton@valpo.edu \\ 2 Department of Mathematics and Statistics, Valparaiso University, Valparaiso, IN 46383, USA; \\ abby.morrow@valpo.edu \\ 3 Institute of Psychology, Faculty of Education and Psychology, Eötvös Loránd University, \\ H-1064 Budapest, Hungary; hevesi.krisztina@ppk.elte.hu \\ * Correspondence: david.rowland@valpo.edu
}

Citation: Rowland, D.L.; Morrow, A.L.; Hamilton, B.D.; Hevesi, K. Do Pornography Use and Masturbation Frequency Play a Role in

Delayed/Inhibited Ejaculation during Partnered Sex? A

Comprehensive and Detailed

Analysis. Sexes 2022, 3, 115-133.

https://doi.org/10.3390/

sexes3010010

Academic Editor: Giagulli

Vito Angelo

Received: 29 December 2021

Accepted: 1 February 2022

Published: 6 February 2022

Publisher's Note: MDPI stays neutral with regard to jurisdictional claims in published maps and institutional affiliations.

Copyright: () 2022 by the authors. Licensee MDPI, Basel, Switzerland. This article is an open access article distributed under the terms and conditions of the Creative Commons Attribution (CC BY) license (https:/ / creativecommons.org/licenses/by/ $4.0 /)$.

\begin{abstract}
The role of masturbation frequency and pornography use on sexual response during partnered sex has been controversial, the result of mixed and inconsistent findings. However, studies investigating this relationship have often suffered from methodological shortcomings. We investigated the role of masturbation frequency and pornography use on both the occurrence and severity of delayed/inhibited ejaculation (DE), an increasingly common sexual problem among men. We did so in a large (nonclinical) multinational sample of cisgender men $(\mathrm{N}=2332$; mean age $=40.3, \mathrm{SE}=0.31$ ) within a multivariate context that relied on multiple (and, when possible, standardized) assessments of sexual dysfunctions while controlling for possible confounding variables. Results indicated a weak, inconsistent, and sometimes absent association between the frequency of pornography use and DE symptomology and/or severity. In contrast, both poorer erectile functioning and anxiety/depression represented consistent and strong predictors of DE and, to a lesser extent, DE severity. Other factors, including relationship satisfaction, sexual interest, and masturbation frequency, were significantly though moderately to weakly associated with DE. In conclusion, associations (or sometimes lack thereof) between masturbation frequency, pornography use, and delayed ejaculation are more clearly understood when analyzed in a multivariate context that controls for possible confounding effects.
\end{abstract}

Keywords: delayed ejaculation; sexual dysfunction; masturbation frequency; pornography use; erectile function; etiology; acquired; lifelong

\section{Introduction}

With increasing access to the Internet, traditional barriers to sexually explicit materials such as public stigma and societal restriction have waned considerably over the past 20 years. Concomitantly, the number and variety of pornographic websites have greatly increased and, in some parts of the world, the viewing of pornography has become commonplace [1-3]. Even in geo-cultural regions having strong interdictions against pornography, access and use have increased steadily over the past 10 years among both men and women, and in particular among sexually diverse individuals [4].

Social restrictions regarding access to pornography have traditionally been predicated on the assumption that it imparts negative effects to individuals and thus to society at large. For years, these effects had been framed primarily as moral or religious issues [5,6]. More recently, the negative consequences of pornography have found secular parallels, often ones involving psychological health and social welfare. Such putative detrimental consequences include negative effects on an individual's sexual response/capacity [7], diminished relationship quality/satisfaction [8], the potential for addiction [9-11], objectification of (particularly) women [12,13], and encouragement of high-risk sexual behaviors [14,15]. At 
the same time, pornography use has sometimes been associated with more benign purposes, such as having an educational function for men, women, and sexually diverse individuals having a limited understanding of sexual practices and behavior [16,17], an erotic/arousal function for both men and women during masturbation [18], and a rehabilitative function for men and women challenged by sexual dysfunctions and disabilities [1]. Couples, too, may incorporate pornography into partnered sex as a means of heightening their sexual interest/desire and arousal [19], with improved sexual communication sometimes resulting as well [20].

\subsection{Effects of Pornography Use on Psychosexual Functioning and Relationship Quality/Satisfaction}

While hypothetical concerns about possible detrimental effects of pornography on psycho-sexual functioning and relationship health are valid, such concerns require empirical support that extends beyond anecdotal/case studies, data from select clinical populations, or ideologically slanted reports-e.g. [5-9]. To date, most research on the effects of pornography use on psychosexual and relationship functioning has generated mixed results, depending on factors such as the specific response variable and how it was defined, the characteristics of the sample under investigation, the nature of the pornography, and the sophistication of the methodological/statistical procedures implemented. However, even when methodological conditions are optimized, results are likely to vary considerably within samples, given the wide variation in people's attitudes toward pornography.

\subsubsection{Pornography Use and Relationship Quality/Satisfaction}

A recent meta-analysis of 50 studies provided evidence for a curvilinear association between frequency of pornography use and sexual relationship satisfaction, with detrimental effects to satisfaction occurring only after exceeding a particular threshold of use in men but not women [21]. A recent survey of 1513 young adults in the United States (nearly $62 \%$ women) also supported a curvilinear association between greater pornography viewing and decreased sexual satisfaction — this time for both men and women-but the acceleration of the curve was more pronounced for men [8]. Detriments to sexual relationship satisfaction were also more pronounced for individuals not currently in a romantic relationship and those identifying as "religious."

Several studies have supported a more qualified interpretation of the relationship between pornography use and sexual relationship satisfaction. In a convenience sample of 803 adults, cluster analyses revealed significant differences among participants using pornography primarily for recreation, those individuals emotionally or psychologically distressed about their pornography use, and compulsive users [22]. Recreational, noncompulsive users-with women comprising $78 \%$ of this cluster-reported greater sexual satisfaction and lower sexual avoidance compared to the other two profiles. Moreover, in a survey of over 1000 adults in the United States, those who viewed pornography together with their partner reported significantly higher sexual satisfaction and greater relationship dedication than respondents who only watched pornographic content alone [23]. With regard to the self-perception of potential benefits and problems arising from pornography consumption, multinational studies have found that, in some instances, both men and women attributed generally positive effects of pornography on their sex life, attitudes toward sex, and life in general [24]; in another case, more frequent pornography use during masturbation was generally associated with more favorable sexual response outcomes during masturbation and partnered sex in women, while not negatively affecting sexual or overall relationship satisfaction [25].

\subsubsection{Pornography Use and Erectile Dysfunction (ED)}

The argument has been made that repeated and consistent pornography use during masturbation, particularly when coupled with a strong auto-erotic orientation, may have deleterious effects on sexual response during partnered sex. The rationale is usually stated along the following lines: Men who have a strong auto-erotic orientation (as manifested by 
their relatively high frequency of masturbation) and/or who use pornography frequently are likely conditioning themselves to stimulus and arousal conditions that do not transfer well to partnered sex, e.g., [26,27]. As a result, these men may experience diminished motivation for "real-life" partnered sex, compounded by difficulty reaching arousal levels sufficient for erection and subsequent ejaculation during partnered sex, where stimulus conditions (both physical and psychological-cognitive) differ substantially.

The above hypothesis has purportedly been supported by circumstantial evidence that notes an increasing prevalence of ED among younger men that is correlated with increasing pornography use, both in society at large and within specific study samples [28,29]. Furthermore, several case studies have drawn attention to the fact that some treatmentseeking men who are frequent pornography users have indeed experienced difficulty with sexual performance within the context of their dyadic relationships $[25,26]$. Such reports have been augmented by a study that showed that among men visiting a urology clinic, a preference for masturbation using pornography over partnered sex was correlated to a lack of satisfactory intercourse [30].

Such studies, however, have typically been fraught with methodological issues, including ones related to small sample sizes or to simple bivariate correlational analyses that do not concomitantly control for possible confounding variables [26-31]. In fact, a number of other studies have suggested no role-or even an opposite and beneficial role-for pornography use on sexual arousal and erectile response [32-34]. In a recent comprehensive review, Dwulit and Rzymski [35] concluded that a causal link between pornography use and erectile problems has yet to be demonstrated, noting methodological issues such as unreliable self-reported erectile dysfunction (ED) (i.e., not using standardized instruments), and interpretation issues regarding a possible opposite directional effect such that men experiencing problems with erection turn to pornography use during masturbation as a means of increasing arousability and sexual satisfaction, rather than vice versa. Thus, while pornography use could play a role in erectile functioning, the effect has only been demonstrated sporadically, suggesting an unstable or weak association, at best.

\subsubsection{Pornography Use and Delayed Ejaculation (DE)}

Another potential role for frequency of pornography use and masturbation has been examined in relationship to delayed ejaculation (DE). Delayed (and/or inhibited) ejaculation is an understudied problem affecting about $5-10 \%$ of men and characterized by difficulty or inability to reach orgasm during partnered sex [36,37]. As the final phase in the sexual response cycle, difficulty reaching orgasm can be affected by other components of sexual response, including low sexual desire, diminished erectile functioning, and inadequate psychological-sexual arousal [38]. DE is usually conceptualized as having two different possible etiologies: Some men have experienced ejaculation-related difficulty for all or the majority of their sexual lives (i.e., lifelong or primary), presumably the result of a biologically predisposed higher threshold to ejaculation; other men experience the difficulty only after a period of normal ejaculatory response, presumably the result of intervening pathophysiological or psychological conditions that actively inhibit the ejaculatory response (i.e., acquired or secondary) [7,37,38].

No matter the origin of the DE problem, the rationale for the connection between pornography use, masturbation frequency, and difficulty reaching orgasm stems from the idea that, as with erectile functioning, frequent masturbation, along with the stimulation provided by pornography use (often strong and appealing to sexual fantasies), interferes with the ability to become sufficiently aroused during partnered sex so as to reach ejaculation $[7,27]$. That is, even though these men may attain adequate erections [39], their overall level of sexual excitement may still be insufficient to exceed the ejaculatory threshold.

Not surprisingly, the topic suffers not only from a dearth of studies in general, but also from a lack of controlled or large-scale cohort studies. In addition, the studies that do exist have produced mixed results. On the one hand, a number of vividly described case studies have implicated pornography use coupled with a high masturbation frequency 
with problems reaching ejaculation [26,27,40-42]. In addition, a study of 115 hypersexual "chronic" masturbators who frequently used pornography noted that $30 \%$ reported some issues with DE [43]. On the other hand, based on clinical reports, some men who have high emotional blocks toward sexual response may benefit from the strong stimulus potential of pornographic materials, which can reportedly overcome the inhibiting effects of guilt and shame on sexual arousal [26]. Furthermore, two large-scale studies drawing on various European populations have found no relationship between pornography use and delayed ejaculation [33,34]. Dwulit and Rzymksi, in their review, concluded that the extent to which pornography use may contribute to DE is currently unresolved, though to date there is little evidence to support a causal link between the two [35]. However, the inability to draw confident conclusions either way-yes it does or no it does not-is the result of a lack of well-powered and well-designed studies specifically aimed at testing this hypothesis.

\subsection{Rationale and Goals}

Thus far, support for a hypothetical role for pornography use on DE during partnered sex has been confined mainly to case studies, select clinical populations, and simple binary analyses. Furthermore, studies have relied on non-standardized assessments of sexual functioning, and they have not controlled for possible confounding variables such as masturbation frequency (a potential correlate of pornography use [35]) or concomitant erectile problems which may interfere with the ability to reach ejaculation [44]. Finally, DE itself has different etiologies, one form being lifelong, the other being acquired [7,36-38], with prior research failing to distinguish between these DE subtypes. As such, much of the prior research investigating this topic has been underpowered, lacked reliable characterization of the sexual dysfunction [35], used highly selective and/or biased samples [43], omitted the assessment of potential confounding variables (e.g., masturbation frequency and concomitant ED) [44], and/or failed to assess the role of pornography use-including its effect size-within a larger multivariate context.

Thus, there is need to investigate the relationship between pornography use and DE within the general population rather than in clinical populations seeking treatment-a selfselected group representing a significant source of bias [44]. Furthermore, any investigation on the topic needs to be both comprehensive and multivariate: Comprehensive, in that it examines the data from different angles and parses out the relative effects of masturbation frequency from pornography use, while also controlling for confounding variables such as levels of erectile functioning and sexual interest; and multivariate, in that it examines the effects of masturbation frequency and pornography use relative to the effects of other variables on sexual response (e.g., DE etiology, relationship satisfaction).

This study examined the relationships between frequency of masturbation and pornography use both on the overall likelihood of suffering from delayed ejaculation/orgasm during partnered sex and, for a subset of men experiencing delayed ejaculation, on the severity of the DE problem. It did so through a comprehensive analysis that used appropriate assessments for sexual dysfunctions while concomitantly controlling for potential confounding covariates.

Specifically, we addressed five research questions:

1. Do men with DE during partnered sex show differences in pornography use (during masturbation) and masturbation frequency compared with men having no ejaculatory disorders (Aim 1).

2. Do DE men having varied etiologies (e.g., lifelong vs. acquired; just DE vs. DE + ED) show differences in pornography use and masturbation frequency (Aims $2 a$ and $2 b$ ).

3. Do pornography use and masturbation frequency, along with relevant demographic and sexual covariates, predict specific indices of DE during partnered sex, such as difficulty reaching orgasm and \% of time reaching ejaculation (Aim 3).

4. Do pornography use and masturbation frequency predict DE symptomology when complicating factors from erectile problems and acquired DE are eliminated from the sample of DE men (Aims 4a and 4b). 
5. Do pornography use and masturbation frequency predict severity of symptoms in a subset of men that includes only those who are experiencing DE (Aim 5).

\section{Materials and Methods}

\subsection{Participants}

Participants were recruited by voluntary self-selection from July 2019 through February 2020 to complete a survey pertaining to sexual health and behavior. The sample was recruited through two approaches. The first group was recruited from the United States and other English-speaking countries $(\mathrm{N}=699)$ and included men who responded to the research homepage, postings on several reddit.com forums, or any of the unpaid social media (e.g., Facebook) and public announcements/advertisements. The second group was recruited from Hungary and included men who responded to comparable forum posts, unpaid online/public advertisements, or the Hungarian research webpage $(\mathrm{N}=3243)$. A final group (not represented in this study sample) consisted of men attending a major university in Hungary $(\mathrm{N}=134)$ who volunteered to take a pencil-and-paper version of the questionnaire. Men in the third group were assigned an anonymous code to enable test-retest comparisons for reliability analysis on specific questionnaire items after 4-6-weeks.

The completion rate for the survey was $81 \%$ of those who initially opened it. Among those completing the survey, men who had never had a sexual partner; identified as "asexual" or transgender/non-binary; reported having premature ejaculation (PE); chose not to ejaculate during partnered sex; or showed inconsistency in responding as determined by embedded "attention checks" in the survey were excluded from the analysis. The final Internet self-selection sample consisted of 2254 men $18+$ years of age (mean $=40.3, \mathrm{SE}=0.31$; range $=18-85)$.

\subsection{Survey Questionnaire}

During the survey development process, a pilot was conducted with seven focus groups. Two focus groups included men in the United States $(\mathrm{N}=10$, mean age $=32.4)$, and five groups included men from Hungary $(\mathrm{N}=79$, mean age $=20.7)$, the latter consisting primarily of university students in several professional and academic disciplines. Group members reviewed the questionnaire items, commenting on their relevance and clarity of phrasing, and suggested both wording changes and additional response categories [45]. Focus groups also appraised item face-validity and assessed the time required for survey completion. For Hungarian respondents, the questionnaire was translated to Hungarian by a professional translator and subsequently back-translated to English to ensure preservation of meaning.

The first part of the 55-item survey queried about demographic characteristics, including the respondent's age, level of educational attainment, anxiety/depression throughout the previous 6 months (as a proxy for psychological health), and any chronic medical conditions related to sexual functioning. The second portion examined participants' sexual histories during the previous 12-24 months, including sexual orientation, number of current sexual partners, self-reported importance of and interest in sex, general relationship satisfaction, and sexual relationship satisfaction. This section also evaluated the frequencies of partnered sex, masturbation, and pornography use during masturbation. The third section addressed common sexual dysfunctions in men and included relevant items from the language-validated versions of International Index of Erectile Function, abridged version (IIEF-5) [46], and the Premature Ejaculation Diagnostic Tool (PEDT) [47], as well as questions aimed at assessing DE (see below).

\subsection{Major Variables of Interest}

Two sets of variables were of primary interest in this analysis: (1) those related to the frequency of pornography use during masturbation, and to masturbation frequency, and (2) those related to assessing DE. In addition, a number of variables were assessed for inclusion as explanatory or control covariates or as a way of reducing error by restricting 
analyses to certain subsamples (e.g., removing men with PE from the control group or, for selected analyses, men with ED). Items on the questionnaire related to these variables are listed in a supplementary materials (Supplementary Tables S1 and S2).

\subsubsection{Assessment of Pornography Use and Masturbation Frequency}

Pornography use during masturbation was evaluated with two questions, using a timeframe reference of the past 12-24 months. Participants were asked if they used erotic materials (with examples provided) during masturbation and if so, what percent of the time they used them. Responses were 0 (I do not use erotic materials), then 1 (rarely or less than $15 \%$ of the time) to 5 (very often or more than $85 \%$ of the time).

Frequency of masturbation was evaluated with a single item, ranging in frequency from 0 (Never) to 10 (more than $4 \mathrm{x} /$ day), with the following incremental intervals $(2=<1 / \mathrm{month}$, $3=$ about $1 \mathrm{x} /$ month, $4=$ once every two weeks, $5=$ about $1 \mathrm{x} / \mathrm{wk}$., $6=$ about $2-3 \mathrm{x} / \mathrm{wk}$., 7 = about $4-6 x /$ wk., $8=$ about $1 x /$ day, $9=$ about $2-3 x /$ day.

\subsubsection{Assessment of Delayed Ejaculation}

No Patient Report Outcomes (PROs) have been developed and validated for assessing DE [37]. As a result, we selected two experimenter-derived items in the questionnaire to assess DE. The first asked respondents about their "difficulty reaching orgasm during partnered sex" (referred to as DE DIFF). Responses were scaled 1-5, with higher scores representing greater difficulty. Generally, for this item, 1-2 represented "no/mild DE",

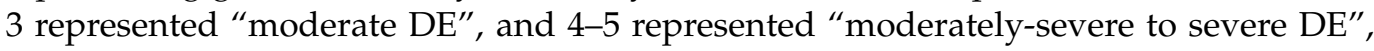
with the 4-5 (severe) category used to define DE men for comparisons across DE and non-DE groups. The second question asked about the estimated percent of time that sexual episodes ended in ejaculation/orgasm during partnered sex (referred to as \%EJACULATION). Responses were recorded on an analog scale ranging from 0 (never) to 100 (always). Participants indicating that they chose not to ejaculate for whatever reason during partnered sex were removed from the analysis.

We also considered inclusion of estimated ejaculation latency as a third measure of DE symptomology, but preliminary analyses indicated that this measure was a less sensitive and reliable measure (insofar as test-retest reliability) than either DE DIFF or \%EJACULATION. The correlation between the two DE outcome indices used herein, DE DIFF and \%EJACULATION, was -0.49 (Spearman rho), indicating that while not redundant, each was tapping into a different aspect of the same general construct.

\subsubsection{Assessment of Control Variables or Covariates}

Erectile dysfunction (ED) during partnered sex was assessed for use as a potential covariate in the regression analyses by using four IIEF- 5 items related specifically to erection [46] (one item focusing on satisfaction during intercourse was not included). Consistent with the scoring rubric for the IIEF-5 [46], for the four selected items, lower scores indicated greater erectile dysfunction.

Premature ejaculation (PE) was assessed for the purpose of ensuring that men constituting the control or "normal ejaculatory functioning" group did not include men with PE. PE was assessed using three of the five items from the PEDT focusing on ejaculatory control, the construct most central to characterizing PE [47]. Two items related to "bother/distress" were not included as they represent consequences of PE. Consistent with the overall diagnostic categories for the PEDT [47], for the included items (scaled 1-5, with higher scores representing greater probability of PE), scores of 13-15 represented "definite $P E$ ", 9-12 represented "probable PE", *" and $\leq 8$ represented "no PE". Those with either probable or definite PE were removed from the sample to ensure that the control/non-DE group consisted of men with normal ejaculatory function.

Several other relevant covariates were included in the regression analyses, including age, problems with ongoing anxiety/depression ( $\geq 6$ months) as a general measure of psychological health/functioning, and having medical issues that could affect sexual 
functioning. A covariate "sexual interest" was constructed from a question from the overall IIEF [48] (rate your sexual desire/interest) and supplemented with a second question on the "importance of sex". These questions tap into the same general construct, being strongly correlated both in this sample $\left(r_{\mathrm{s}}=0.71\right)$ as well as in other research $[44,49]$, so they were combined to generate a composite variable "sexual interest" (SI). Finally, in a preliminary cleaning of data, several differences were noted regarding national origin (origin-of-data), so this measure was included as a control covariate in all analyses.

For three key variables - cumulative PEDT, IIEF, and SI-test-retest correlations were 0.85 or higher when assessed 4-6 weeks later. For variables related to DE, test-retest reliability for DE DIFF and \%EJACULATION was 0.70 and 0.84 , respectively.

\subsection{Procedure}

Ethics approval for the study was obtained from the Institutional Review Boards (IRB) at the authors' institutions in both the United States and Hungary. The 55-item online survey took approximately $20 \mathrm{~min}$ to complete. Participants were guaranteed anonymity, and safeguards were implemented to prevent multiple submissions. Informed consent was obtained by participants' checking boxes attesting (1) to their current age being $\geq 18$ years, and (2) to their informed consent before accessing the questionnaire. Respondents were notified that they could end participation at any time by closing the webpage.

\subsection{Analytical Strategy}

We explored connections between masturbation, pornography use, and DE in a variety of ways so as to gain a deep understanding of the relationships among these factors, both individually and within the context of larger multivariate analyses. As noted previously, men with probable or definite PE were removed from the analysis to ensure that the group "with normal ejaculatory function" did not include men suffering from this dysfunction. Furthermore, because the origin-of-data (USA+ vs. Hungarian) also emerged as significant across several measures, it was included as a control covariate in all analyses.

Using ANCOVA, we then assessed whether differences emerged between pornography use and masturbation frequency based on DE status during partnered sex (moderateto-severe DE vs. normal ejaculatory function) in the overall sample. We followed with post hoc analyses to determine whether (1) men with DE complicated by ED differed from men with just DE (which we refer to as "pure" DE), and whether (2) men with lifelong (LL) DE differed from men with acquired DE. Age and origin-of-data were included as covariates.

Then, using linear regression, we explored the extent to which masturbation frequency, pornography use, and a set of empirically and/or theoretically relevant covariates were able to predict indices of DE, using DE DIFF and \%EJACULATION as proxy outcome variables. We used a four-step process, first entering all the relevant covariates, including IIEF scores (a measure of erectile functioning) and using a sample of all men meeting the inclusion criteria, that is, both those with and without DE. Second, we removed those men suffering from ED (i.e., such that only men with pure DE were included in the overall sample), and re-ran the analysis to determine if either masturbation frequency or pornography use frequency emerged as a significant predictor. Third, we then further excluded those men whose DE was acquired later in life, enabling us to restrict the analysis to a subset of men having "pure/lifelong (LL)" DE. And fourth, we used the block entry method to determine whether frequency of masturbation and (separately) pornography use significantly added to the explained variance in DE measures for either the "pure" or the "pure/LL" men (see Appendix A for defining characteristics of samples and subsamples).

A similar strategy was used to predict the severity of DE symptoms, but for these analyses we restricted the outcome variables only to the ranges that likely characterized men with DE (see Results). We also added DE etiology-whether lifelong or acquired-to the set of predictor covariates, and progressively restricted the sample from all men with DE to "pure" DE men, and then finally, to "pure/lifelong" DE (Appendix A), removing DE etiology for this last analysis. 
All analyses were carried out with SPSS (IBM Corp. Released 2017. IBM SPSS Statistics for Windows, Version 25.0, Armonk, NY, USA).

\section{Results}

\subsection{Description of the Sample}

Table 1 describes characteristics of men with and without DE. Men who reported moderate to severe difficulty reaching orgasm were more likely to report anxiety/depression or to have a medical issue that affected sexual functioning $(p<0.001)$. They reported lower frequency of partnered sex $(p<0.001)$ and lower sexual interest $(p=0.028)$, as well as lower sexual relationship and overall relationship satisfaction ( $p<0.001$ for both). Because of these differences, non-collinear variables were included as predictor covariates in the regression analyses.

Table 1. Descriptions (mean $\pm \mathrm{SD}$ ) of men with normal ejaculatory response and men with delayed/inhibited ejaculation (DE) on demographic and sexual/relationship variables.

\begin{tabular}{cccc}
\hline Variable & $\begin{array}{c}\text { Normal Ejaculation } \\
(\mathbf{N}=\mathbf{1 5 5 6 )}\end{array}$ & $\begin{array}{c}\text { Delayed Ejaculation }^{2} \\
(\mathbf{N}=\mathbf{2 3 4})\end{array}$ & -Value $^{3}$ \\
\hline Age & $4.2(12.6)$ & $4.8(13.7)$ & 0.522 \\
\hline Education & $2.9(1.6)$ & $2.8(1.5)$ & 0.856 \\
\hline Anxiety/depression (\% yes) & 14 & 28 & $<0.001$ \\
\hline Medical Issues (\% yes) & 21 & 25 & $<0.001$ \\
\hline Sexual Interest (SI) (1-10 scale) & $8.5(1.4)$ & $8.3(1.6)$ & 0.028 \\
\hline Frequency of Partnered Sex & $6.4(1.6)$ & $5.8(1.8)$ & 0.001 \\
\hline $\begin{array}{c}\text { Sexual Relationship } \\
\text { Satisfaction (1-5 scale) }\end{array}$ & $3.7(1.1)$ & $3.2(1.3)$ & $<0.001$ \\
\hline $\begin{array}{c}\text { Overall Relationship } \\
\text { Satisfaction (1-5 scale) }\end{array}$ & $4.1(1.0)$ & $3.7(1.1)$ & $<0.001$ \\
\hline
\end{tabular}

Notes: ${ }^{1}$ Normal Ejaculation group excludes men with premature ejaculation and includes only those men reporting no or low difficulty reaching ejaculation. ${ }^{2}$ Delayed Ejaculation group includes men reporting moderate to severe difficulty reaching ejaculation. ${ }^{3}$ Comparisons were made with the $t$-test or, for percentages, with the z-test for comparing proportions.

\subsection{DE and non-DE Group Differences in Masturbation Frequency and Pornography Use (Aim 1)}

No/Low vs. Moderately Severe to Severe DE DIFF. In this first analysis we compared masturbation frequency and frequency of pornography use between men low on DE DIFF (i.e., those having normal ejaculatory function) and men high on DE DIFF, including age and origin-of-data as control covariates (Table 2). Men with higher DE DIFF showed higher frequencies of both masturbation $(p=0.017)$ and pornography use $(p=0.006)$ than men with no/low DE DIFF, although effect sizes were small. Interpolated values within response categories [50] estimated that DE men used pornography about $72 \%$ of the time, whereas non-DE men used pornography about $53 \%$ of the time. DE men masturbated about $1.7 \mathrm{x}$ /week whereas control (non-DE) men masturbated about $1.2 \mathrm{x} /$ week. 
Table 2. Comparisons of Masturbation Frequency and Pornography Use (mean \pm standard deviation in men with delayed ejaculation (DE) ${ }^{1}$ vs. normal/control, DE with vs. without erectile dysfunction (ED), and lifelong vs. acquired groups ${ }^{2}$.

\begin{tabular}{ccc}
\hline Group & Frequency of Masturbation ${ }^{3}$ & Pornography Use $^{3}$ \\
\hline $\mathrm{DE}(n=234)$ & $5.6(2.3)$ & $4.0(1.6)$ \\
\hline Normal $/$ Control $(n=1572)$ & $5.2(2.3)$ & $3.6(1.8)$ \\
\hline$p$-value & 0.017 & 0.006 \\
\hline Partial $\eta^{2}$ & $0.003^{4}$ & 0.014 \\
\hline $\mathrm{DE}$ without ED $(n=171)$ & $5.8(2.2)$ & $4.2(1.5)$ \\
\hline $\mathrm{DE}$ with ED $(n=59)$ & $5.6(2.3)$ & $3.9(1.6)$ \\
\hline$p$-value & 0.256 & 0.048 \\
\hline Partial $\eta^{2}$ & 0.006 & 0.017 \\
\hline $\mathrm{DE}$ lifelong $(n=74)$ & $6.6(1.9)$ & $4.4(1.1)$ \\
\hline $\mathrm{DE}$ acquired $(n=99)$ & $5.5(2.2)$ & $4.0(1.6)$ \\
\hline$p$-value & 0.144 & 0.451 \\
\hline Partial $\eta^{2}$ & 0.013 & 0.003 \\
\hline
\end{tabular}

Note: ${ }^{1}$ Categorization of DE was based on the item "difficulty reaching orgasm during partnered sex" and included only men responding 4 or 5 on a $1-5$ scale. ${ }^{2}$ For all analyses, age and origin-of-data were entered as control covariates. ${ }^{3}$ See text for response categories. ${ }^{4}$ To interpret effect sizes as indicated by partial $\eta^{2}$, $0.02=$ small, $0.13=$ medium, $0.26=$ large .

\subsection{Masturbation Frequency and Pornography Use in DE Men with Varying Etiologies (Aims 2a,b)}

Pure DE vs. comorbid DE + ED. Because difficulty reaching orgasm/ejaculation in DE men may be mediated by some men's inability to get an erection, men having only DE (pure DE) were compared with men having comorbid DE + ED, with age and origin-of-data included as control covariates (Table 2). Men with pure DE indicated a higher frequency of pornography use than men with comorbid DE + ED $(p=0.048)$.

Lifelong vs. Acquired DE. A second set of post hoc analyses compared men having lifelong DE with men having acquired DE, including age and origin-of-data as control covariates. DE subtypes did not differ on either frequency of masturbation or pornography use (Table 2).

\subsection{Pornography Use and Masturbation Frequency as Predictors of DE Indices (Aims 3 and 4)}

The two outcome variables analyzed in Aim 1-frequency of masturbation and frequency of pornography use-were significantly correlated (Spearman $\mathrm{r}_{\mathrm{S}}=0.302, p<0.001$ ), indicating that about $9 \%$ of the variance in pornography use could be accounted for by the higher frequency of masturbation. The following set of regression analyses were aimed at parsing out the concomitant and independent associations between, on the one hand, a set of predictor variables that included pornography use and masturbation frequency, as well as other relevant variables impinging on sexual response, and on the other hand, outcome indices for DE, namely DE DIFF and \%EJACULATION.

3.4.1. DE DIFF: Self-Reported "Difficulty Reaching Orgasm during Partnered Sex" as an Index of DE

For regression on this outcome variable, all men (Overall: with and without DE) were included except those reporting PE. Predictor variables included the two key variables of pornography use and masturbation frequency, along with age, IIEF score (i.e., erectile functioning), medical issues likely affecting sexual responses, ongoing anxiety or depression, level of sexual interest (SI), relationship satisfaction, and origin-of-data (Table 3). By far the strongest predictor of DE DIFF was poorer erectile function $(p<0.001)$, followed by anxiety/depression $(p<0.001)$. Higher frequency of masturbation, higher frequency 
of pornography use, and lower relationship satisfaction also predicted greater difficulty reaching orgasm $(p \leq 0.016)$, but with lower though similar effect sizes among them.

Table 3. Results of regression analysis using difficulty reaching orgasm (DE DIFF) and percent of time reaching ejaculation (\%EJACULATION) as outcome variables when DE was unrestricted (Overall), was restricted by removing all men with ED (Pure DE), or was restricted by removing all men with ED or acquired DE (Pure/Lifelong (LL) DE). Masturbation frequency and pornography use frequency are highlighted by darker gray shade.

\begin{tabular}{|c|c|c|c|c|c|c|c|}
\hline \multirow{2}{*}{ Predictor Covariate } & \multirow{2}{*}{$p$ and Beta } & \multicolumn{3}{|c|}{ DE DIFF } & \multicolumn{3}{|c|}{$\%$ EJACULATION } \\
\hline & & Overall & Pure & Pure/LL & Overall & Pure & Pure/LL \\
\hline \multirow{2}{*}{ Age } & $p$-value & 0.795 & 0.008 & 0.502 & 0.003 & 0.512 & 0.032 \\
\hline & beta-coefficient & -0.019 & 0.067 & -0.019 & 0.067 & 0.009 & 0.058 \\
\hline \multirow{2}{*}{ Erectile Function } & $p$-value & $<0.001$ & -1 & - & $<0.001$ & - & - \\
\hline & beta-coefficient & -0.0357 & - & - & 0.381 & - & - \\
\hline \multirow{2}{*}{ Anxiety } & $p$-value & $<0.001$ & $<0.001$ & $<0.001$ & 0.064 & 0.005 & 0.003 \\
\hline & beta-coefficient & 0.085 & 0.119 & 0.099 & -0.038 & -0.059 & -0.068 \\
\hline \multirow{2}{*}{ Sexual Interest } & $p$-value & 0.096 & 0.001 & 0.001 & $<0.001$ & $<0.001$ & $<0.001$ \\
\hline & beta-coefficient & -0.033 & -0.073 & -0.080 & 0.076 & -0.131 & 0.120 \\
\hline Relationship & $p$-value & 0.001 & 0.001 & $<0.001$ & 0.008 & $<0.001$ & $<0.001$ \\
\hline Satisfaction & beta-coefficient & -0.068 & -0.093 & -0.088 & 0.043 & 0.155 & 0.135 \\
\hline \multirow{2}{*}{ Medical Issue } & $p$-value & 0.954 & 0.067 & 0.139 & 0.801 & 0.131 & 0.690 \\
\hline & beta-coefficient & 0.001 & 0.041 & 0.036 & 0.005 & -0.024 & -0.010 \\
\hline \multirow{2}{*}{$f$ Masturbation } & $p$-value & 0.016 & 0.009 & 0.105 & 0.068 & 0.014 & 0.087 \\
\hline & beta-coefficient & 0.052 & 0.063 & 0.046 & -0.049 & -0.062 & -0.047 \\
\hline \multirow{2}{*}{$f$ Pornography Use } & $p$-value & $<0.001$ & 0.001 & 0.029 & 0.242 & 0.197 & 0.124 \\
\hline & beta-coefficient & 0.076 & 0.073 & 0.059 & 0.015 & 0.024 & 0.041 \\
\hline \multirow{2}{*}{ Origin of Data } & $p$-value & 0.003 & 0.002 & 0.069 & $<0.001$ & 0.087 & $<0.001$ \\
\hline & beta-coefficient & 0.062 & 0.071 & 0.046 & -0.122 & -0.034 & -0.130 \\
\hline Overall Adjusted $\mathrm{R}^{2}$ & & 0.177 & 0.055 & 0.041 & 0.219 & 0.076 & 0.073 \\
\hline
\end{tabular}

Note: ${ }^{1}-=$ Not applicable as the variable was not included in the analysis.

Because the strongest predictor of DE DIFF was erectile functioning, we ran a followup regression in which men with ED were excluded (leaving only the men with "pure" DE) (Table 3). Our rationale was that men with pure DE would not be confounded by their inability to get or sustain an erection, which could interfere with ejaculation. These analyses indicated that anxiety was the strongest predictor of DE DIFF $(p<0.001)$. Other predictors were similar in their associations, and included increasing age, lower sexual interest, lower relationship satisfaction, higher frequency of masturbation, and higher frequency of pornography use $(p \leq 0.009)$.

In a third analysis, using the same set of predictor variables, we restricted the men with DE to only those with a lifelong (LL) condition and without concomitant ED (pure/LL). For these analyses, anxiety/depression, lower sexual interest, lower relationship satisfaction, and higher frequency of pornography use were significantly associated with DE DIFF $(p \leq 0.029)$ (Table 3).

Finally, we determined the additional amount of explained variance from including masturbation frequency and pornography use by using the block entry regression method for the three separate analyses that included all DE men, only men with the pure DE, and only men with the pure/LL DE (Table 4). The first block included the three variables that most consistently predicted DE DIFF (see above), namely anxiety, relationship satisfaction, and SI. The IIEF score was included as a 4th variable in this block when men with ED were included in the analysis. The second and third blocks included masturbation frequency and pornography use, respectively. The first and second blocks (i.e., including masturbation frequency) were significant for all DE men, pure DE men, and pure/LL DE men, whereas pornography use was not (Table 4). Masturbation frequency and pornography use increased the amount of explained variance $\left(\Delta R^{2}\right)$ by less than $0.8 \%$ and $0.6 \%$, respectively. 
Table 4. Summary of block entry method $(1,2,3)$, showing the additional explained variance of DE symptomology ( $\Delta \mathrm{R} 2)$ due to inclusion of frequency of masturbation and pornography use (grey shade).

\begin{tabular}{|c|c|c|c|c|c|c|c|}
\hline \multirow{3}{*}{ Predictor Covariate } & \multirow{3}{*}{ Block } & \multicolumn{3}{|c|}{ DE DIFF } & \multicolumn{3}{|c|}{ \%EJACULATION } \\
\hline & & All DE & Pure & Pure/LL & All DE & Pure & Pure/LL \\
\hline & & $\Delta R^{2}$ & $\Delta R^{2}$ & $\Delta \mathrm{R}^{2}$ & $\Delta \mathbf{R}^{2}$ & $\Delta \mathrm{R}^{2}$ & $\Delta R^{2}$ \\
\hline Erectile Function & 1 & & $\mathrm{NA}^{3}$ & NA & & NA & NA \\
\hline Anxiety & 1 & $0.161^{1}$ & $0.037^{1}$ & $0.035^{1}$ & $0.194^{1}$ & $0.056^{1}$ & $0.072^{1}$ \\
\hline Sexual Interest & 1 & & & & & & \\
\hline Relationship Satisfaction & 1 & & & & & & \\
\hline$f$ Masturbation & 2 & $0.008^{1}$ & $0.006^{1}$ & $0.005^{1}$ & 0.002 & $0.006^{1}$ & 0.002 \\
\hline$f$ Pornography Use & 3 & 0.006 & 0.004 & 0.003 & 0.000 & 0.000 & 0.001 \\
\hline
\end{tabular}

Notes: ${ }^{1}$ Indicates $p<0.05$ for $\mathrm{R}^{2}$ or the $\Delta \mathrm{R}^{2} .{ }^{3} \mathrm{NA}=$ not applicable.

\subsection{2. \%EJACULATION: Percent of Time Reaching Ejaculation as an Index of DE}

In a second set of analyses (please refer to Table 3), when all men were included except those with PE, poorer erectile functioning was by far the strongest predictor of \%EJACULATION $(p<0.001)$, followed by lower relationship satisfaction $(p=0.008)$. Other significant predictors of \%EJACULATION included age, sexual interest, and relationship satisfaction $(p \leq 0.008)$. Neither masturbation frequency nor pornography use was significant $(p \geq 0.068)$.

Because the strongest predictor \%EJACULATION was erectile functioning, we ran a follow-up regression in which men with ED were excluded, leaving only men with pure DE (Table 3). Lower sexual interest and relationship satisfaction were the stronger predictors of \%EJACULATION $(p<0.001)$, with anxiety and masturbation frequency also significant $(p \leq 0.014)$. Again, pornography use was not significant $(p=0.197)$.

In a third analysis, using the same set of predictor variables, we restricted the men with DE to only those with lifelong DE and without concomitant ED (pure/LL DE men). For these analyses, anxiety/depression, lower sexual interest, and lower relationship satisfaction were significantly associated with \%EJACULATION $(p \leq 0.029)$ (Table 3$)$. Neither masturbation frequency nor pornography use was significant $(p \geq 0.087)$.

Finally, we determined the amount of increased variance explained by including masturbation frequency and pornography use by using the block entry regression method for separate analyses that included all DE men, only men with the pure DE, or only men with pure/LL DE, using the same strategy as outlined for DE DIFF above. The second block relating to masturbation frequency was significant only for pure DE men (Table 4); the third block relating to pornography use was not significant for any of the DE groupings. Furthermore, the change in $\Delta \mathrm{R}^{2}$ was small, $\leq 0.6 \%$ for masturbation frequency, and $\leq 0.1 \%$ for pornography use.

\subsection{Pornography Use and Masturbation Frequency as Predictors of DE Severity (Aim 5)}

In this set of analyses, we investigated only those men with symptoms of DE, with the aim of determining whether masturbation frequency and/or pornography use predicted the severity of DE during partnered sex. Restrictions on the two DE indices were as follows: For DE DIFF, we restricted the outcome variable to only those men indicating moderate-tosevere difficulty reaching orgasm, that is, $3-5$ on this measure, representing roughly $1 \mathrm{SD}$ above the mean. For \%EJACULATION, we included only those men who ejaculated $70 \%$ of the time or less during partnered sex, a cutoff represented by about 1 SD below the mean.

\subsubsection{DE DIFF as an Index of DE Severity}

In addition to using the set of predictor variables for the unrestricted sample, we included a variable differentiating lifelong vs. acquired DE etiology. The only significant predictors of DE severity were poorer erectile functioning and lifelong (vs acquired) DE etiology ( $p=0.003$ and 0.028 , respectively). Neither pornography use nor masturbation frequency were significant predictors of DE DIFF ( $p=0.097$ and 0.842 , respectively). Because 
ED was the strongest predictor of DE severity in the previous analysis, we ran a follow up regression in which men with ED were excluded, leaving only men with pure DE in the analysis. Only lifelong DE etiology was significant $(p=0.006)$. When we further restricted the sample to include only men with pure/LL DE, none of the variables, including pornography use or masturbation frequency, was associated with DE severity $(p=0.276$ and 0.413 , respectively).

\subsection{2. \%EJACULATION as an Index of DE Severity}

In a second set of analyses, we assessed predictor variables for \%EJACULATION for men who indicated that they ejaculated $70 \%$ of the time or less during partnered sex. Both lower erectile functioning and lower relationship satisfaction significantly predicted lower \%EJACULATION ( $p=0.001$ and 0.004 , respectively). Neither masturbation frequency nor pornography use was associated with lower \%EJACULATION ( $p=0.138$ and 0.692, respectively). Because erectile functioning was the strongest predictor of DE severity, we repeated the analyses in a subset of men with pure DE. For these analyses, lower relationship satisfaction and lifelong DE etiology predicted lower \%EJACULATION $(p=0.011$ and 0.048 , respectively). Neither masturbation frequency nor pornography use were significant ( $p \geq 0.613$ ). When we further restricted the sample to include only men with pure/LL $\mathrm{DE}$, none of the variables, including pornography use or masturbation frequency, was associated with DE severity ( $p=0.921$ and 0.925 , respectively).

\section{Discussion}

Pornography use has been and continues to be a controversial issue for any number of reasons. Insofar as its relationship to sexual dysfunction, we believe the current study - using a large Internet-based multinational (nonclinical) sample, relying on multiple indices to assess delayed ejaculation, and including a number of contextual and potential confounding covariates-provides an opportunity to examine the impact of masturbation frequency and pornography use on both DE symptomology and DE severity in a more holistic framework than most previous studies on this topic. Furthermore, by progressively restricting the sample of men with DE from all such men, to only those without concomitant ED (pure DE men), and then only to men with lifelong DE and without concomitant ED (pure/LL DE men), we were able to understand how specific covariates were associated with DE using various definitions of DE status.

\subsection{Reiteration and Summary of Major Findings}

4.1.1. Differences between DE and Normal/Control Groups, as Well as DE Groups Having Various Etiologies

At first glance, our results suggest that both masturbation frequency and pornography use play relevant roles in DE, as both behaviors were higher among DE men than men with normal ejaculatory response. Post hoc analyses comparing men having pure DE with men having comorbid DE and ED revealed slightly higher pornography use among men with pure DE. In contrast, comparison of men with lifelong and acquired DE indicated no differences on either variable between DE etiological subtypes. Where differences did occur, effect sizes were notably small, particularly in comparison with other predictor covariates included in the regression analyses (see below).

\subsubsection{Factors Predicting DE Symptomology within the Overall Sample}

Had our analyses ended with the results of the above ANCOVAs, our conclusions might have been misleading, as subsequent regression analyses-in which recurring patterns of association and relative effect sizes could be identified-led to a more nuanced interpretation. In these analyses, in addition to pornography use and masturbation frequency, other variables likely to affect sexual/ ejaculatory response were entered as predictor covariates, including age, erectile functioning, anxiety/depression, sexual interest, 
relationship satisfaction, chronic medical conditions known to affect sexual response, and, for testing the severity of symptoms, DE subtype (acquired or lifelong).

As seen in Table 3, beta coefficients in the regression analyses, although not a precise index of effect size, offer a rough estimate of the importance of masturbation frequency and pornography use to DE symptomology, in comparison with other relevant predictor covariates: specifically, those variables having higher coefficients generally indicate greater relevance of the predictor variable to the outcome variable.

In order to simplify the results and to illustrate patterns of significance across regression analyses, we created summary tables of the relative effects of predictor covariates for the two indices for DE status, and also for DE severity (Tables 5 and 6). These tables are most easily read by viewing the number of $x^{\prime}$ s in the row pertaining to any specific variable, with a greater number of $x^{\prime}$ s indicating more consistent and stronger associations.

Table 5. Summary of variable effects showing consistency in patterns of predictor covariates in the overall sample, in the sample that included men with pure DE, and in the sample that included men with pure/lifelong (LL) DE ${ }^{1}$. Effects of frequency of masturbation and frequency of pornography use are grey-shaded for emphasis.

\begin{tabular}{cccccccc}
\hline \multirow{2}{*}{ Predictor Covariate } & \multicolumn{3}{c}{ DE DIFF } & \multicolumn{3}{c}{ \%EJACULATION } \\
\cline { 2 - 7 } & All DE Men & Pure & Pure/LL & All DE Men & Pure & Pure/LL \\
\hline Age & - & $\mathrm{x}$ & & $\mathrm{x}$ & - & $\mathrm{x}$ \\
Erectile Function & $\mathrm{xxx}$ & $\mathrm{NA}$ & $\mathrm{NA}$ & $\mathrm{xxx}$ & $\mathrm{NA}$ & $\mathrm{NA}$ \\
Anxiety & $\mathrm{xx}$ & $\mathrm{xx}$ & $\mathrm{x}$ & - & $\mathrm{xx}$ & $\mathrm{x}$ \\
Sexual Interest & - & $\mathrm{x}$ & $\mathrm{x}$ & $\mathrm{x}$ & $\mathrm{xx}$ & $\mathrm{xx}$ \\
Relationship Satisfaction & $\mathrm{x}$ & $\mathrm{x}$ & $\mathrm{x}$ & $\mathrm{x}$ & $\mathrm{xx}$ & $\mathrm{xx}$ \\
Medical Issue & - & - & - & - & - & - \\
$f$ Masturbation & $\mathrm{x}$ & $\mathrm{x}$ & - & - & $\mathrm{x}$ & - \\
$f$ Pornography Use & $\mathrm{x}$ & $\mathrm{x}$ & $\mathrm{x}$ & - & - & - \\
Origin of Data & $\mathrm{x}$ & $\mathrm{x}$ & - & $\mathrm{xx}$ & $\mathrm{x}$ & $\mathrm{xx}$ \\
\hline Overall Adjusted $\mathrm{R}^{2}$ & 0.180 & 0.055 & 0.041 & 0.219 & 0.076 & 0.073 \\
\hline
\end{tabular}

Notes: ${ }^{1}$ Based on significant beta coefficients, $\mathrm{x}=$ weaker effect, $\mathrm{xx}=$ moderate effect, $\mathrm{xxx}=$ stronger effect $-=$ not significant.

Table 6. Patterns of variable associations in the subset of men having DE symptoms, showing the lack of significant association between frequency of masturbation or pornography use (both grey-shaded for emphasis), and DE severity ${ }^{1}$.

\begin{tabular}{ccccccc}
\hline \multirow{2}{*}{ Predictor Covariate } & \multicolumn{3}{c}{ DE DIFF } & \multicolumn{3}{c}{$\%$ EJACULATION } \\
\cline { 2 - 7 } & All DE & Pure & Pure/LL & All DE & Pure & Pure/LL \\
\hline Age & - & - & & - & - & \\
Erectile Function & $\mathrm{xx}$ & NA & NA & $\mathrm{xxx}$ & NA & NA \\
Anxiety & - & - & - & - & - & - \\
Sexual Interest & - & - & - & - & - & - \\
Relationship Satisfaction & - & - & - & $\mathrm{xx}$ & $\mathrm{xx}$ & - \\
Medical Issue & - & - & - & - & - & - \\
$f$ Masturbation & - & - & - & - & - & - \\
$f$ Pornography Use & - & - & - & - & - & - \\
DE Subtype: LL vs. & $\mathrm{xx}$ & $\mathrm{xx}$ & $\mathrm{NA}$ & - & $\mathrm{x}$ & NA \\
Acquired & - & - & - & - & - & - \\
Origin of Data & 0.071 & 0.052 & 0.027 & 0.114 & 0.084 & 0.04 \\
\hline Overall Adjusted R ${ }^{2}$ & & &
\end{tabular}

Notes: ${ }^{1}$ Based on beta coefficients, $\mathrm{x}=$ weaker effect, $\mathrm{xx}=$ moderate effect, $\mathrm{xxx}=$ stronger effect $;-=$ not significant.

Referring to Table 5, when the sample included the full range of men both with and without DE, poorer erectile functioning was the strongest predictor of DE symptomology. Anxiety/depression was also a consistent though less strong predictor of DE indices, 
including in DE groups that were restricted to men with lifelong DE and without concomitant ED. Relationship satisfaction and sexual interest were also fairly consistent-though weaker-predictors of DE symptomology. Masturbation frequency and pornography use were among the least consistent and weakest of the DE predictors. And in fact, for \%EJACULATION, a slightly more reliable variable than DE DIFF, pornography use had no significant association with DE. The block entry method revealed that knowing the respondent's masturbation frequency improved explained variance in DE symptomology by only $0.8 \%$ or less; knowing their pornography use either did not improve explained variance at all, or did so by under $0.6 \%$ (as seen previously in Table 4 ).

\subsubsection{Factors Predicting DE Severity}

Table 6 shows that poorer erectile functioning was also the strongest predictor of $\mathrm{DE}$ severity, reiterating the role of erectile functioning on DE in general. In addition, lower relationship satisfaction was sporadically related to greater DE severity. Lifelong DE etiology (as opposed to acquired DE) emerged as a relevant factor in predicting DE severity. Neither masturbation frequency nor pornography use was associated with the severity of DE symptomology, whether the sample included all DE men, men with just pure DE, or men with pure/LL DE.

\subsection{General Interpretation and Integration of Findings}

Our analyses demonstrated that the association between pornography use and DE symptomology/severity was generally weak or absent in this nonclinical (primarily Western) sample. Furthermore, when the strong effect of erectile problems on DE symptomology and/or severity was removed by including only men with "pure" DE—or even when the potential for pathophysiologically based DE was eliminated by including only men with lifelong PE-pornography use did not consistently emerge as a salient variable. The overall low or absent effect sizes related to pornography use may explain some of the mixed results from prior studies-see [34]. Specifically, variables imparting weak effects tend to be vacillating, often appearing and disappearing across studies depending on the specific methodology, the inclusion (or omission) of relevant control covariates, and the specific characteristics of the sample [51,52].

While our study demonstrates that pornography use provides little or no explained variance in DE symptomology-either within the overall (nonclinical) sample or more specifically within a subset of men exhibiting specific DE symptomology-we do not dismiss the idea that a high frequency of pornography use could interfere with achieving adequate levels of arousal during partnered sex in some men, as has been suggested in a number of clinical/case studies [26,27,42]. That is, men's sexual experiences and histories undoubtedly play an important role in their sexual responsivity, and excessive pornography use may well constitute a risk factor for sexual problems in specific subsets of highly vulnerable men, e.g., for those having little or no partnered experiences [42]. Nevertheless, in contrast to suggestions inferred from some prior research, our analysis did not support a widespread and/or robust relationship between pornography use and DE symptomology.

Higher masturbation frequency may offer a limited explanation for DE symptomology, at least for some men. Like pornography use, it emerged sporadically as a predictor of DE symptomology, showing only intermittent associations and relatively small effect sizes. Although a role for an auto-erotic orientation involving stereotypical and frequent masturbation on DE has been supported by several clinical reports [26,40], such cases may represent exceptions- that is, the most intractable of DE cases showing up at clinics for treatment. Even so, in a cross-sectional study such as ours, no clear direction of effect between masturbation frequency and DE indices could be ascertained, leaving open the possibility that men may masturbate more frequently (and supplement it with pornography use to enhance their arousal) as a consequence of experiencing difficulty ejaculating, rather than vice versa. In the absence of clear causal directionality, we assume a reciprocating 
model whereby some men who are predisposed to difficulty reaching ejaculation during partnered sex may increasingly turn to masturbation and pornography use for sexual pleasure but who, in doing so, might also intensify any problem they have of reaching ejaculation during partnered sex [53,54].

In contrast with relatively weak or absent associations between masturbation frequency or pornography use and DE symptomology, lower erectile functioning stood out as a highly salient predictor of both DE occurrence and DE severity. In fact, when men with ED were removed from the analysis, the level of explained variance in DE symptomology dropped by nearly $70 \%$ in the overall sample. The relationship between erectile functioning and DE symptomology was not surprising, as a significant percent of men suffering from DE also report ED $[44,55,56]$. Within this subgroup, men's inability to get or sustain an erection undoubtedly interferes with their capacity to reach ejaculation-a point that underscores the importance of the clinician's differentiation of DE caused by erectile insufficiency vs. DE caused by insufficient psycho-sexual arousal and/or other etiological factors $[39,44]$. Indeed, our study, while demonstrating a very limited association between pornography use and DE symptomology in men with pure DE, did not rule out a possible relationship between pornography use and impaired erectile functioning, as suggested by several studies [27-30].

Of the other predictor covariates, anxiety/depression (as a measure of general psychological health) also stood out as a fairly common predictor of DE status (less so of DE severity), whether or not the group included men with ED. Anxiety related to DE is also not surprising, as this construct has long been associated with sexual impairment [57-61]. What is not clear from our study design is whether the anxiety may have actually contributed to the problem, or is merely a consequence of the problem. Most likely, it functions as both-as anxiety related to sexual performance typically results from the "evaluative" nature of partnered sex, thus eliciting a self-perpetuating cycle of anxiety and failure $[59,61]$.

Other factors associated with DE symptomology/severity were relationship satisfaction and level of sexual interest. Diminished relationship satisfaction undoubtedly occurs as men struggle to reach ejaculation during partnered sex-a finding that aligns with a broader pattern of diminished relationship quality resulting from nearly any type of sexual problem [62-65]. On the other hand, the relationship between lower sexual interest and greater DE symptomology/severity is less readily explained. We surmise that men who place lower importance on-and investment in-their sex lives may suffer from diminished sexual desire, which in turn negatively affects their levels of sexual excitement and ability to reach orgasm - a rationale that led to inclusion of this variable as a control covariate in our regression analyses.

DE subtype - whether lifelong or acquired-also played a role in DE severity, although neither group was more prone to engage in frequent masturbation or pornography use. Men with lifelong DE consistently showed greater symptomology than men with acquired DE. To help understand this difference, we conducted a post hoc analysis that revealed that men with acquired DE were slightly older than men with lifelong DE. However, even when age was controlled, men with lifelong DE reported greater difficulty and less likelihood of reaching orgasm during partnered sex. We offer no persuasive explanation to account for this difference, but note that it parallels to some extent differences in short ejaculation latencies in men with lifelong vs. acquired premature ejaculation (PE) [66-70]. As such, there is need for greater investigation of the interactive roles of erectile functioning, low sexual interest, and etiological subtype on DE symptomology and severity $[68,69]$.

\subsection{Limitations}

This study was multinational in scope, well-powered $(1-\beta=0.99+)$, and multivariate in analysis, and it relied on standardized items/scales when available. Nevertheless, we note several limitations. For one, although we implemented best practices for online survey research [45,71] by taking precautions to guarantee anonymity, including attention checks to eliminate cases having inconsistent responses across the survey, and steps to prevent 
multiple submissions, online surveys that rely heavily on public and social media for recruitment are subject to biases in education, class, social media access, and other factors. Second, our study did not rule out possible relationships between masturbation frequency, pornography use, and erectile functioning - relationships that require investigation within a more targeted multivariate analysis. Third, we note that our results may not apply to many regions of the world where cultural attitudes regarding sexuality are more restrictive, where masturbation and/or pornography use may be strongly associated with sinfulness, guilt, shame, and even punishment. Indeed, given the wide individual and cultural variation in attitudes toward pornography, we would expect differences to occur across various geo-cultural world regions. Related to this point, we did not assess the nature/type of pornography that was being viewed-some types could have more detrimental effects than others. Fourth, as a cross-sectional study, we cannot ascribe causal relationships among our principal study variables. And finally, we do not presume that our study provides closure to the question regarding the relationships among masturbation, pornography use, and DE, as such relationships are likely to dynamically vary across both generations and cultures. Rather, we encourage other research teams to carry out well-controlled studies using a variety of methodologies that operationally define and assess both outcome variables and predictor/confounding variables.

\section{Conclusions}

The association between pornography use and delayed ejaculation was very limited or absent in our sample, whereas other factors, particularly erectile functioning and anxiety/depression, were salient predictors of DE indices. Relationship satisfaction, sexual interest, and masturbation frequency were also associated with DE, although their effects were less consistent and not as strong. Finally, the weak effect of pornography use should not discount the possibility that it might help explain DE symptomology in specific subsets of vulnerable men-particularly those who are less experienced and/or who masturbate excessively [35,72].

Supplementary Materials: The following are available online at https://www.mdpi.com/article/10 .3390 / sexes3010010/s1, Table S1: Survey questions for the regression covariates, Table S2: Survey questions for the outcome variables related to Delayed/Inhibited Ejaculation.

Author Contributions: Conceptualization, D.L.R., K.H.; methodology, D.L.R., B.D.H. and K.H.; formal analysis, D.L.R., B.D.H., and A.L.M.; investigation, D.L.R., B.D.H., A.L.M. and K.H.; resources, D.L.R. and K.H..; data curation, B.D.H. and A.L.M.; writing-original draft preparation, D.L.R.; writing—review and editing, D.L.R., K.H., B.D.H. and A.L.M.; visualization, B.D.H. and A.L.M. All authors have read and agreed to the published version of the manuscript.

Funding: This research received no external funding.

Institutional Review Board Statement: Valparaiso University IRB 19-001.

Informed Consent Statement: Informed consent was obtained from all subjects involved in the study.

Data Availability Statement: Output files are available for inspection upon reasonable request to the corresponding author.

Conflicts of Interest: The authors declare no conflict of interest. 


\section{Appendix A}

Description of samples and their characteristics used in the analyses, indicating the progressive restrictions placed on each sample.

\begin{tabular}{|c|c|}
\hline FOR ANALYSIS OF DE & \multirow{2}{*}{ Characteristics } \\
\hline Analyses on the entire sample & \\
\hline Normal Ejaculatory Function (NEF) & Men having no premature ejaculation (as assessed by the PEDT) or DE symptoms \\
\hline $\mathrm{NEF}+$ Overall DE & NEF and all men reporting DE \\
\hline NEF + Pure DE & NEF and men reporting DE, but minus all men reporting ED \\
\hline NEF + Pure/Primary DE & NEF and only men with lifelong DE, and minus all men reporting ED \\
\hline \multicolumn{2}{|l|}{ FOR ANALYSIS OF DE SEVERITY } \\
\hline Analysis on DE men defined by: & Characteristics \\
\hline "Difficulty reaching orgasm" & Reporting either 3,4 , or 5 , representing approximately 1 SD above the mean \\
\hline "Percent episodes ejaculating" & Reporting $70 \%$ or less, representing approximately 1 SD below the mean \\
\hline
\end{tabular}

3.4.2. \%EJACULATION: Percent of Time Reaching Ejaculation as an Index of DE.

\section{References}

1. Kirby, M. Pornography and its impact on the sexual health of men. Trends Urol. Men's Health 2021, 12, 6-10. [CrossRef]

2. Solano, I.; Eaton, N.R.; O'Leary, K.D. Pornography consumption, modality and function in a large internet sample. J. Sex. Res. 2018, 57, 92-103. [CrossRef]

3. Herbenick, D.; Fu, T.-C.; Wright, P.; Paul, B.; Gradus, R.; Bauer, J.; Jones, R. Diverse sexual behaviors and pornography use: Findings from a nationally representative probability survey of americans aged 18 to 60 years. J. Sex. Med. 2020, 17, 623-633. [CrossRef]

4. $\quad$ Rowland, D.L.; Uribe, D. Pornography Use: What Do Cross-Cultural Patterns Tell Us? In Cultural Differences and the Practice of Sexual Medicine: A Guide for Sexual Health Practitioners; Springer International Publishing: Cham, Switzerland, 2020.

5. Harper, K. From Shame to Sin: The Christian Transformation of Sexual Morality in Late Antiquity; Harvard University Press: Cambridge, MA, USA, 2013.

6. Thomas, J.N. The development and deployment of the idea of pornography addiction within American evangelicalism. Sex. Addict. Compulsivity 2016, 23, 182-195. [CrossRef]

7. Perelman, M.A.; Rowland, D.L. Retarded and Inhibited Ejaculation. In Handbook of Sexual and Gender Identity Disorders; Rowland, D.L., Incrocci, L., Eds.; John Wiley \& Sons, Inc.: Hoboken, NJ, USA, 2008; pp. 100-121.

8. Wright, P.J.; Bridges, A.J.; Sun, C.; Ezzell, M.B.; Johnson, J.A. Personal pornography viewing and sexual satisfaction: A quadratic analysis. J. Sex Marital Ther. 2017, 44, 308-315. [CrossRef]

9. Magness, M.S. Stop Sex Addiction: Real Hope, True Freedom for Sex Addicts and Partners; Central Recovery Press: Las Vegas, NV, USA, 2013.

10. Grubbs, J.B.; Stauner, N.; Exline, J.J.; Pargament, K.I.; Lindberg, M.J. Perceived addiction to internet pornography and psychological distress: Examining relationships concurrently and over time. Psychol. Addict. Behav. 2015, 29, 1056-1067. [CrossRef]

11. Gola, M.; Wordecha, M.; Sescousse, G.; Lew-Starowicz, M.; Kossowski, B.; Wypych, M.; Makeig, S.; Potenza, M.N.; Marchewka, A. Can pornography be addictive? An fMRI study of men seeking treatment for problematic pornography use. Neuropsychopharmacology 2017, 42, 2021-2031. [CrossRef] [PubMed]

12. Mikorski, R.; Szymanski, D.M. Masculine norms, peer group, pornography, Facebook, and men's sexual objectification of women. Psychol. Men Masculinities 2017, 18, 257-267. [CrossRef]

13. Peter, J.; Valkenburg, P.M. Adolescents and pornography: A review of 20 years of research. J. Sex Res. 2016, 53, 509-531. [CrossRef]

14. Eaton, L.A.; Cain, D.N.; Pope, H.; Garcia, J.; Cherry, C. The relationship between pornography use and sexual behaviours among at-risk HIV-negative men who have sex with men. Sex. Heal. 2012, 9, 166-170. [CrossRef]

15. Harkness, E.L.; Mullan, B.; Blaszczynski, A. Association between pornography use and sexual risk behaviors in adult consumers: A systematic review. Cyberpsychol. Behav. Soc. Netw. 2015, 18, 59-71. [CrossRef]

16. Rothman, E.F.; Daley, N.; Alder, J. A pornography literacy program for adolescents. Am. J. Public Health 2020, 110, 154-156. [CrossRef]

17. Spišák, S. 'Everywhere they say that it's harmful but they don't say how, so I'm asking here': Young people, pornography and negotiations with notions of risk and harm. Sex Educ. 2016, 16, 130-142. [CrossRef]

18. Chadwick, S.B.; Raisanen, J.; Goldey, K.L.; Van Anders, S. Strategizing to make pornography worthwhile: A qualitative exploration of women's agentic engagement with sexual media. Arch. Sex. Behav. 2018, 47, 1853-1868. [CrossRef]

19. Staley, C.; Prause, N. Erotica viewing effects on intimate relationships and self/partner evaluations. Arch. Sex. Behav. 2012, 42, 615-624. [CrossRef] 
20. Daneback, K.; Træen, B.; Månsson, S.-A. Use of pornography in a random sample of norwegian heterosexual couples. Arch. Sex. Behav. 2008, 38, 746-753. [CrossRef] [PubMed]

21. Wright, P.J.; Tokunaga, R.S.; Kraus, A.; Klann, E. Pornography consumption and satisfaction: A meta-analysis. Hum. Commun. Res. 2017, 43, 315-343. [CrossRef]

22. Vaillancourt-Morel, M.P.; Blais-Lecours, S.; Labadie, C.; Bergeron, S.; Sabourin, S.; Godbout, N. Profiles of cyberpornography use and sexual well-being in adults. J. Sex. Med. 2017, 14, 78-85. [CrossRef] [PubMed]

23. Maddox, A.M.; Rhoades, G.; Markman, H.J. Viewing sexually-explicit materials alone or together: Associations with relationship quality. Arch. Sex. Behav. 2009, 40, 441-448. [CrossRef] [PubMed]

24. Hald, G.M.; Malamuth, N.M. Self-perceived effects of pornography consumption. Arch. Sex. Behav. 2007, 37, 614-625. [CrossRef] [PubMed]

25. McNabney, S.M.; Hevesi, K.; Rowland, D.L. Effects of pornography use and demographic parameters on sexual response during masturbation and partnered sex in women. Int. J. Environ. Res. Public Heal. 2020, 17, 3130. [CrossRef]

26. Perelman, M.A. Psychosexual therapy for delayed ejaculation based on the Sexual Tipping Point model. Transl. Androl. Urol. 2016, 5, 563-575. [CrossRef]

27. Park, B.Y.; Wilson, G.; Berger, J.; Christman, M.; Reina, B.; Bishop, F.; Klam, W.P.; Doan, A.P. Is internet pornography causing sexual dysfunctions? A review with clinical reports. Behav. Sci. 2016, 6, 17. [CrossRef] [PubMed]

28. Janssen, E.; Bancroft, J. The dual control model: The role of sexual inhibition and excitation in sexual arousal and behavior. In The Psychophysiology of Sex; Janssen, E., Ed.; Indiana University Press: Bloomington, IN, USA, 2007; pp. 197-222.

29. Wéry, A.; Billieux, J. Online sexual activities: An exploratory study of problematic and non-problematic usage patterns in a sample of men. Comput. Hum. Behav. 2016, 56, 257-266. [CrossRef]

30. Berger, J.H.; E Kehoe, J.; Doan, A.P.; Crain, D.S.; Klam, W.P.; Marshall, M.T.; Christman, M.S. Survey of sexual function and pornography. Mil. Med. 2019, 184, 731-737. [CrossRef] [PubMed]

31. Grubbs, J.B.; Gola, M. Is pornography use related to erectile functioning? Results from cross-sectional and latent growth curve analyses. J. Sex. Med. 2019, 16, 111-125. [CrossRef]

32. Prause, N.; Pfaus, J. Viewing sexual stimuli associated with greater sexual responsiveness, not erectile dysfunction. Sex. Med. 2015, 3, 90-98. [CrossRef] [PubMed]

33. Pizzol, D.; Bertoldo, A.; Foresta, C. Adolescents and web porn: A new era of sexuality. Int. J. Adolesc. Med. Heal. 2016, 28, 169-173. [CrossRef] [PubMed]

34. Landripet, I.; Štulhofer, A. Is pornography use associated with sexual difficulties and dysfunctions among younger heterosexual men? J. Sex. Med. 2015, 12, 1136-1139. [CrossRef]

35. Dwulit, A.D.; Rzymski, P. The potential associations of pornography use with sexual dysfunctions: An integrative literature review of observational studies. J. Clin. Med. 2019, 8, 914. [CrossRef]

36. Butcher, M.J.; Serefoglu, E.C. Treatment of Delayed Ejaculation. In The Textbook of Clinical Sexual Medicine; IsHak, W., Ed.; Springer International Publishing: New York, NY, USA, 2017; pp. 255-269.

37. Rowland, D.L. A conceptual approach to understanding and managing men's orgasmic difficulties. Urol. Clin. N. Am. 2021, 4, 577-590. [CrossRef]

38. American Urological Association. Disorders of ejaculation: An AUA /SMSNA guideline. Available online: https://www.auanet. org/guidelines/disorders-of-ejaculation (accessed on 17 January 2022).

39. Rowland, D.L.; Keeney, C.; Slob, A.K. Sexual response in men with inhibited or retarded ejaculation. Int. J. Impot. Res. 2004, 3, 270-274. [CrossRef]

40. Bronner, G.; Ben-Zion, I.Z. Unusual masturbatory practice as an etiological factor in the diagnosis and treatment of sexual dysfunction in young men. J. Sex. Med. 2014, 7, 1798-1806. [CrossRef] [PubMed]

41. Rodríguez, J.; López, A. Male masturbation device for the treatment of premature ejaculation. Asian Pac. J. Reprod. 2016, 1, 80-83. [CrossRef]

42. Blair, L. How difficult is it to treat delayed ejaculation within a short-term psychosexual model? A case study comparison. Sex. Relatsh. Ther. 2018, 3, 298-308. [CrossRef]

43. Sutton, K.S.; Stratton, N.; Pytyck, J.; Kolla, N.J.; Cantor, J.M. Patient characteristics by type of hypersexuality referral: A quantitative chart review of 115 consecutive male cases. J. Sex Marital Ther. 2015, 6, 563-580. [CrossRef] [PubMed]

44. Rowland, D.L.; Oosterhouse, L.B.; Kneusel, J.A.; Hevesi, K. Comorbidities among sexual problems in men: Results from an internet convenience sample. Sex. Med. 2021, 9. [CrossRef]

45. Catania, J.A.; Dolcini, M.M.; Orellana, R.; Narayanan, V. Nonprobability and probability-based sampling strategies in sexual science. J. Sex. Res. 2015, 52, 396-411. [CrossRef]

46. Rosen, R.C.; Cappelleri, J.C.; Smith, M.D.; Lipsky, J.; Peña, B.M. Development and evaluation of an abridged, 5-item version of the International Index of Erectile Function (IIEF-5) as a diagnostic tool for erectile dysfunction. Int. J. Impot. Res. 1999, 6, 319-326. [CrossRef] [PubMed]

47. Symonds, T.; Perelman, M.A.; Althof, S.; Giuliano, F.; Martin, M.; May, K.; Abraham, L.; Crossland, A.; Morris, M. Development and validation of a premature ejaculation diagnostic tool. Eur. Urol. 2007, 2, 565-573. [CrossRef]

48. Rosen, R.C.; Riley, A.; Wagner, G.; Osterloh, I.H.; Kirkpatrick, J.; Mishra, A. The International Index of Erectile Function (IIEF): A multidimensional scale for assessment of erectile dysfunction. Urol. J. 1997, 49, 822-830. [CrossRef] 
49. Rowland, D.L.; Kolba, T.N. Relationship of specific sexual activities to orgasmic latency, pleasure, and difficulty during partnered sex. J. Sex. Med. 2019, 16, 559-568. [CrossRef] [PubMed]

50. Samarin, M.K. Linear Interpolation. Available online: http://www.encyclopediaofmath.org/index.php?title=Linear_ interpolation\&oldid=27068 (accessed on 17 January 2022).

51. Rowland, D.L.; Cote-Leger, P. Moving toward empirically based standardization in the diagnosis of delayed ejaculation. J. Sex. Med. 2020, 10, 1896-1902. [CrossRef] [PubMed]

52. Rowland, D.L.; Motofei, I.G. Experimental models in sexual medicine: Eight best practices. In Sexual Dysfunctions in Mentally Ill Patients; Jannini, E.A., Siracusano, A., Eds.; Springer International Publishing AG: New York, NY, USA, 2018.

53. Perelman, M. Delayed ejaculation. In Principles and Practice of Sex Therapy, 6th ed.; Hall, K.S., Binik, Y.M., Eds.; Guilford Press: New York, NY, USA, 2020; pp. 156-179.

54. Rowland, D.L.; Hamilton, B.D.; Bacys, K.R.; Hevesi, K. Sexual response differs during partnered sex and masturbation in men with and without sexual dysfunction: Implications for treatment. J. Sex. Med. 2021, 18, 1835-1842. [CrossRef] [PubMed]

55. Kasman, A.M.; Bhambhvani, H.P.; Eisenberg, M.L. Ejaculatory dysfunction in patients presenting to a men's health clinic: A retrospective cohort study. Sex. Med. 2020, 3, 454-460. [CrossRef] [PubMed]

56. Lewis, R.W.; Fugl-Meyer, K.S.; Bosch, R.; Fugl-Meyer, A.R.; Laumann, E.O.; Lizza, E.; Martin-Morales, A. Epidemiology/risk factors of sexual dysfunction. J. Sex. Med. 2004, 1, 35-39. [CrossRef]

57. Barlow, D.H. Causes of sexual dysfunction: The role of anxiety and cognitive interference. J. Consult. Clin. Psychol. 1986, 2, 140-148. [CrossRef]

58. Rowland, D.L.; Kolba, T.N. The burden of sexual problems: Perceived effects on men's and women's sexual partners. J. Sex Res. 2018, 2, 226-235. [CrossRef]

59. Rowland, D.L.; Moyle, G.; Cooper, S.E. Remediation strategies for performance anxiety across sex, sport and stage: Identifying common approaches and a unified cognitive model. Int. J. Environ. 2021, 19, 1016. [CrossRef]

60. Yafi, F.A.; Jenkins, L.; Albersen, M.; Corona, G.; Isidori, A.M.; Goldfarb, S.; Maggi, M.; Nelson, C.J.; Parish, S.; Salonia, A.; et al. Erectile dysfunction. Nat. Rev. Dis. 2016, 2, 16003. [CrossRef]

61. Bancroft, J. Churchill Livingstone Elsevier. In Human Sexuality and its Problems, 3rd ed.; Taylor, A., Urquhart, J., Eds.; Elsevier Limited: London, UK, 2009.

62. Manjula, V.; Manjula, M.K.; Navaneetham, J.; Philip, M. Quality of marital relationship and sexual interaction in couples with sexual dysfunction: An exploratory study from India. J. Psychosex. Health 2021, 4, 332-341. [CrossRef]

63. Fisher, W.A.; Eardley, I.; McCabe, M.; Sand, M. Erectile dysfunction (ED) is a shared sexual concern of couples: Couple conceptions of ED. J. Sex. Med. 2009, 6, 2746-2760. [CrossRef]

64. Rosen, R.C.; Althof, S. Impact of premature ejaculation: The psychological, quality of life, and sexual relationship consequences. J. Sex. Med. 2008, 6, 1296-1307. [CrossRef] [PubMed]

65. Rowland, D.L. Psychological impact of premature ejaculation and barriers to its recognition and treatment. Curr. Med. Res. Opin. 2011, 8, 1509-1518. [CrossRef] [PubMed]

66. McMahon, C.G.; Giuliano, F.; Dean, J.; Hellstrom, W.J.G.; Bull, S.; Tesfaye, F.; Sharma, O.; Rivas, D.A.; Aquilina, J.W. Efficacy and safety of dapoxetine in men with premature ejaculation and concomitant erectile dysfunction treated with a phosphodiesterase type 5 inhibitor: Randomized, placebo-controlled, phase III study. J. Sex. Med. 2013, 10, 2312-2355. [CrossRef] [PubMed]

67. Gao, J.; Zhang, X.; Su, P.; Liu, J.; Xia, L.; Yang, J.; Shi, K.; Tang, D.; Hao, Z.; Zhou, J.; et al. Prevalence and factors associated with the complaint of premature ejaculation and the four premature ejaculation syndromes: A large observational study in China. $J$. Sex. Med. 2013, 10, 1874-1881. [CrossRef] [PubMed]

68. Serefoglu, E.C.; Yaman, O.; Cayan, S.; Asci, R.; Orhan, I.; Usta, M.F.; Ekmekcioglu, O.; Kendirci, M.; Semerci, B.; Kadioglu, A. Prevalence of the complaint of ejaculating prematurely and the four premature ejaculation syndromes: Results from the turkish society of andrology sexual health survey. J. Sex. Med. 2011, 2, 540-548. [CrossRef] [PubMed]

69. Côté-Léger, P.; Rowland, D.L. Estimations of typical, ideal, premature ejaculation, and actual latencies by men and female sexual partners of men during partnered sex. J. Sex. Med. 2020, 8, 1448-1456. [CrossRef] [PubMed]

70. Rowland, D.; Teague, L.; Hevesi, K. Premature ejaculation measures during partnered sex and masturbation: What these findings tell us about the nature and rigidity of premature ejaculation. J. Sex Marital Ther. (under review).

71. Kays, K.M.; Keith, T.L.; Broughal, M.T. Best Practice in Online Survey Research with Sensitive Topics. In Advancing Research Methods with New Technologies; IGI-Global: Hershey, PA, USA, 2013; pp. 157-168. [CrossRef]

72. Hoagland, K.C.; Grubbs, J.B. Pornography use and holistic sexual functioning: A systematic review of recent research. Curr. Addict. Rep. 2021, 8, 408-421. [CrossRef] 